\title{
The Business Competitiveness and Future Proposing of Alibaba Group
}

\author{
Yihao Lu ${ }^{1, \dagger}$ Qihang Zhang ${ }^{2, \dagger}$ Lifu Wang $^{3,{ }^{\dagger}}$ Yi Zhang ${ }^{4, \dagger}$
}

\author{
${ }^{I}$ Kings College of Western University Ontario. \\ ${ }^{2}$ Xiamen University. \\ ${ }^{3}$ Bengbu College of Technology and Business. \\ ${ }^{4}$ University of New South Wales. \\ *Corresponding author's e-mail: ${ }^{a} y l u 564 @ u w o . c a,{ }^{b} 17420182201038 @$ stu.xmu.edu.cn, ${ }^{c} 1027580557 @ q q . c o m$, \\ dzhangy1004_hf@163.com \\ These authors contribute equally.
}

\begin{abstract}
This paper focused on analysing the core business structure, the status quo, and try to give out several proposals of the future of both the Alibaba group and the ant group, twins which occupied an indispensable position in the internet market of China. The twins have changed the lives of people in China and other countries forever, however, they have to face a changing world. So, it is valuable for us to understand them deeply. The paper analysis the twins in four aspects. The first aspect explored Alibaba cloud, the important cloud computing service department of Alibaba from several questions which include whether the Alibaba Cloud could defeat every competitor in China and Global by the analysis of the information of financing, technology, and marketing; The second part dissect the Cainiao Network, which set up by Alibaba group and four competitive express company, and the growing ability of it with discussing the cooperation, competition, and the market capacity; The third angle, supported by the analysing of the market situation and powerful rivals of E-commerce in China or oversea, answer whether the Alibaba group could become the greatest and strongest E-commerce corporation in the world; The fourth aspect try to analysis the prosperity and the business model of the internet finance, which is the field the Ant group occupied in, and propose the future of China's fintech. Supported by former researches and analysis, the paper concludes the former four aspects. Firstly, with the Matthew Effect, Alibaba cloud could dominate the cloud computing industry in China by its technology advantages. What is more, though facing the rat race with competitors overseas, the technology and platform basic can keep Alibaba cloud on growth; Secondly, Even though the Cainiao Network are fighting fierce with other companies like JD, SF, it has a big growth space of growth and thus brings a mass benefit to Alibaba group. in the future. Thirdly, the drastic global competition makes the Alibaba group could not become the dominating company in the E-commerce field. The best ending of Alibaba is occupying a stable status in the E-commerce market with other tycoons like Amazon. Finally, the analysis of China fintech proposes the internet financial field may be direct participated by China government.
\end{abstract}

Keywords: Alibaba, Cloud computing, Overseas E-commerce, Logistics, Fintech

\section{INTRODUCTION}

Alibaba was established in 1999 in Hangzhou, China. From its initial development to the present, Alibaba has been involved in many fields such as e-commerce, finance, cloud computing, logistics, etc. Alibaba, as one of the leading e-commerce companies in China, had achieved many amazing achievements in these fields. On September 19, 2014, Alibaba Group was officially listed on the New York Stock Exchange, and it also set a record for the largest IPO in history. Then on November 26, 2019, Alibaba's Hong Kong stocks were listed, with a total market value of over 4 trillion. From the establishment of Alibaba to the present, Alibaba Group has been developing positively, and the speed of development is extremely fast. The fields that Ali is involved in are developing very rapidly, such as the initial e-commerce, to the current cloud computing field. The fields that Alibaba covers have brought great benefits to itself. Ali had also become a first-class 
company in the world. Although the current world and China's form has some impact on Ali, it cannot stop Ali's growth in the future. The growth of Ali from before to now is visible in China and the world, and it has not shown a trend of decline. Alibaba has been at the forefront of development in China and the world in cloud computing, e-commerce, modern logistics, and financial technology. These fields have brought huge profits to Ali now, and with Ali's current development trends in these fields, these fields will also bring huge benefits to Ali in the future. Developments in these areas have also enabled Alibaba to show considerable future growth.

$\mathrm{Yu}$ et al. analyzes the innovation of E-commerce financial service product based on cloud computing. It takes Alibaba as an example, comparing with the traditional financial service model. Finally, it is concluded that Alibaba finance has changed the traditional financial service model. It makes use of cloud computing to decline the cost and increase working efficiency and helping small and micro business to get financial services. [1] Shi et al. analyze the development of cloud computing in China. It takes Alibaba. Cloud as an example to analyze its background and finance, and cites some relevant policies to prove the development of cloud computing. Finally, it is concluded that development of the cloud computing is an inevitable trend in China.[2] Mei analyzes the competition of cloud computing. It introduces some cloud providers and their business. Analyzing their operation structure, development and their market share. Finally, it is concluded that Matthew's effect will be more obvious in the cloud computing industries. [3]

Hanand Gan analyse the problem of the application of big data in logistics and its impact on logistics enterprises. It takes the way of Cainiao Network as an example, and gradually analyzing the impact of big data on logistics. It is concluded that the application of big data will promote the development of the logistics industry, and there will be an epoch-making role in supervision, decision-making, customer relations, and resource allocation. [4] Yeet al. analyses the forecast of freight logistics delay and its application prospects in logistics decision-making and management systems. It uses big data to collect appropriate freight data and uses Mat-lab related tools and artificial neural networks for simulation training and analysis of simulation results. It is concluded that the BP neural network model is more accurate than the freight delay prediction. It makes the logistics decision-making system more perfect in actual application. In the network environment, it can be used as strong support for the e-commerce system. However, in the complex social and natural environment. Adjust indicators for different regions and environments to make predictions more scientific. [5] Tanet al. analyses the network structure of the large express service network and the importance of dynamics of package transportation for performance evaluation, network optimization, and user experience enhancement. It collects delivery tracking by modeling the traffic dynamics in China ExpressNet and extend the Extended Markov Model (EMM) to capture the delivery process and predict delays. It is concluded that by inferring the network structure, studying the spatial and temporal characteristics of the network, as well as EMM's dynamic description of package transportation, and delay prediction, it will bring better express shipping services to both service providers and customers. [6]

$\mathrm{Lu}$ analyses the background and other basic information of Ant Financial, the important relative corporation of Alibaba. The Fintech products of Ant Financial, especially the Alipay, changed the lives of people in China and other countries deeply. Hence, the writer implied that the problems like monopoly and destruction to the traditional financial system, and the threat from the social and economic environment of China should be considered. [7]

Zhao analyses the virtuous cycle in the Ant Financial corporation itself and another virtuous circle made by Alibaba and Ant Financial together. Supported by the examples like the different services and systems of the corporation, Y Zhao points out that the special business model of this company should be studied. [8] Qiu analyses the business model of Ant Financial and the strength and the opportunity of the company. What is more, exampled by data and news, the paper proposed some accommodations which may be useful to the global extension of Ant. [9]

Zhao et al. researched a conceptual model, which was suitable for analysing B2B e-markets in China, to aid in evaluating the value creation strategy in the B2B market. Based on a case study of two Chinese e-markets, a process-oriented approach is used to address the two main factors, transaction process and controlling complexity and offer an approach for studying the dynamic structure of e-commerce processes. [10] Hussain et al. analyses the usability of the Lazada mobile application, which was conducted using 12 users of age 18 to 24 , based on evaluating perceived effectiveness, efficiency and satisfaction of the mobile application, to provide positive feedback that the mobile shopping app is effective, efficient and satisfying. [11] Laruccia and Maia analysed the influence of social networks in postpurchase, which used a data collection procedure, The Scup tool to obtain the record of the consumers' behaviour about the post-purchase process. Based on the data, research shows that social networks have changed the relationship between companies and their publics and retailers like AliExpress need to improve customer experience throw social media. [12]

The purpose of this research is to analyse Alibaba's major business and future incremental businesses to judge the future valuation of Alibaba, which help investors and internal managers better understand and 
conduct business related to Alibaba. According to the open and detailed information and data, Alibaba is compared with other competitive companies to explore the future growth of Alibaba Cloud business, to assess the effects of developing Cainiao Network business, to forecast the market share of global e-commerce business and to identify the factors that affect Fintech developing in China.

\section{CLOUD COMPUTING}

Alibaba Cloud was established in 2009, it is a leading global company of cloud computing and AI technology company, As the first company to start cloud services in China, it provides Big Data Analysis, Storage, IoT, Network Security and others service products. At present, Alibaba Cloud is one of the three largest providers of laaS in the world and it is also the largest public cloud service provider in China.

Besides Alibaba Cloud, there are also many cloud services providers in China, such as Tencent, Baidu, Huawei. However, Alibaba Cloud is an early entrant in the cloud computing market, by virtue of its massive investment and technically mature, it successfully occupied most of the cloud computing market share in China. According to the 2020Q4 China Cloud Market Report released by Canalys, Alibaba Cloud accounts for $40.3 \%$ of the market share, Huawei Cloud accounts for $17.4 \%$, Tencent Cloud accounts for $14.9 \%$ and Baidu Cloud accounts for $8.4 \%$.

\section{Market Share(China)}

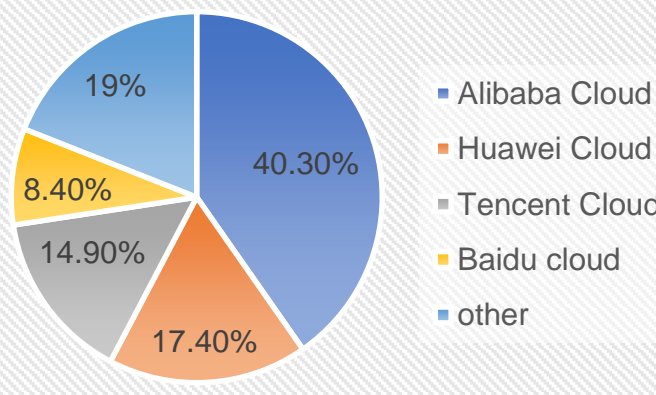

Figure 1 Market share of cloud computing in China

Compared with other cloud services providers, Alibaba Cloud succeeded in winning a nearly half share in the Chinese cloud market. That means Alibaba Cloud has strong competitiveness, and its products are popular with consumers in China. On the one hand, a huge market shore may help Alibaba Cloud reduce the competitive pressure of other competitors, especially new cloud services provider; On the other hand, a huge market shore will help Alibaba Cloud to generate a side effect, reducing the average cost of products or services and obtaining monopoly profit. So, only providers like Alibaba Cloud, Tencent Cloud and Huawei Cloud can rely on their own advantages of market popularity and scale efficiency to be stronger and stronger. Obviously, Alibaba Cloud is the best one in China. That is one of the important reasons why Matthew effect is so obvious in the cloud market.

In addition, the core competitiveness of the Alibaba Cloud is also an important factor, it helps Alibaba Cloud dominate the cloud market in China. Firstly, Alibaba Cloud independently developed a computing operating system_-Apsara", which is the first computing engine developed by our country, and it has stronger computing power and lower computing cost. It proves Alibaba Cloud is more strong than other Chinese cloud providers in computing technology. At the same time, the brand effect of "Apsara" will help Alibaba Cloud obtain revenue continuously. Secondly, "Alibaba Cloud Security Services" safely deploy global business for consumers. Alibaba Cloud adheres to International security and compliance standards, and it undergoes regular third-party evaluations and reviews from numerous certification authority agencies. With the help from the Alibaba Cloud, some international enterprises such as KingSouq, Shiseido, AirAsia and HK express have successfully resisted web-based attacks and distributed denial of service (DDoS) attacks many times. Besides this, Alibaba Cloud successfully helped a wellknown game company resist the largest DDoS attack in history and this event put it on the map. Therefore, "Alibaba Cloud Security Services" has been maturely applied in the international market not only obtains profits but also expands its international market share. At present, Alibaba Cloud has become a leader of the cloud services providers in the APAC. In the future, Alibaba Cloud may rely on its excellent business capabilities in the Asia Pacific region to expand to other international regions. Finally, Alibaba Cloud has opened 63 availability zones in 21 different regions and deployed more than 200 Apsaras data centers all over the world.

The following picture describes all availability zones are deployed by Alibaba Cloud.

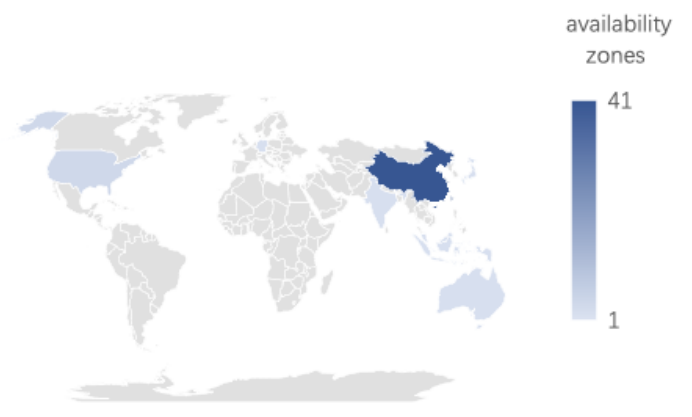

Figure 2 The distribution of availability zones of Alibaba Cloud

Through this picture, we can know that numerous availability zones of Alibaba Cloud can give customers the ability to operate production applications and 
databases that are more highly available, fault-tolerant, and scalable than other Chinese cloud providers. Compared with other Chinese cloud services providers, Alibaba Cloud has regional advantages. For example, Huawei Cloud had 39 availability zones that are less than the Alibaba Cloud. A larger number of the availability zones maybe help Alibaba Cloud have a wider range of its business. Maybe in the future, its business may become more diversified in the different regions and in line with local cultural characteristics, Alibaba will be more competitive in the market.

Because of the above three points, it can be concluded that Alibaba Cloud dominates the cloud computing industry with great advantages in China, and it has the ability to maintain this position.

Compared with foreign cloud services providers, Alibaba Cloud still faces a great challenge. For now, besides Alibaba Cloud, there are also have cloud services providers like AWS, Microsoft, IBM and Google in the world, they are all world-class companies. According to IDC research, in 2020, AWS still occupy nearly half of the international market share $(46.8 \%)$, followed by Microsoft (14.2\%), Alibaba Cloud (7.6\%), Google $(4.8 \%)$ and IBM $(3.7 \%)$.

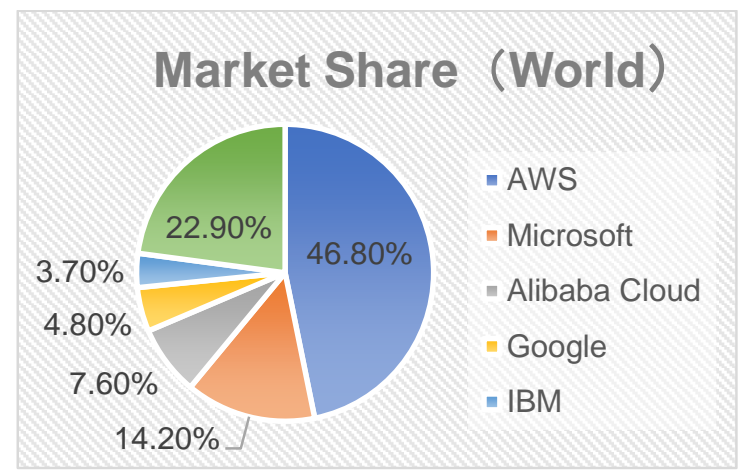

Figure 3 Market share of cloud computing in the world

In addition, AWS, Microsoft and Google, all belong to the first-order cloud computing market in the world, more International consumers prefer their products, and they are more globalized than the third-placed Alibaba Cloud in the international market. The reason for this is that AWS, Microsoft and Google are the most famous Internet companies in America. Based on the leading position of America in the economy, politics, science and technology in the world, more and more international consumers think cloud services from America are higher technological content than cloud services from other countries, especially developing countries. And the choice of consumers can help these cloud service providers from the United States to enhance their international reputation and expand their market share. That is the reasons why the globalization of AWS, Microsoft and Google is stronger than Alibaba Cloud from China. Moreover, Alibaba Cloud ranks third in the world cloud computing market share is due to the help of the huge Chinese cloud computing market. Therefore, Alibaba Cloud still needs to rely on itself to expand its business globalization capability, which will be a big challenge.

But in fact, Alibaba Cloud still has the advantage to compete with the international provider. First of all, the computing power of Alibaba Cloud ranks top in the world. According to the latest product evaluation, (include computing power, storage, network and laaS basic capably) report of cloud providers released by Gartner, the computing power of Alibaba Cloud ranks first in the world with a score of $92.3 \%$. However, compared with AWS, AWS ranks first in storage, network and laasS basic capably. It can be seen that AWS is still a leader in technology. In contrast, Microsoft and Google have nearly the same scores as Alibaba Cloud, or even slightly lower than Alibaba Cloud. The analysis shows that the ability of Alibaba Cloud is not inferior to Microsoft and Google. Alibaba Cloud has the ability to maintain and surpass the international cloud service leader in technology, but it is still a big challenge facing Amazon.

Table 1. The rank of computing power

\begin{tabular}{|c|c|c|c|c|}
\hline Rank & $\begin{array}{c}\text { computing } \\
\text { power }\end{array}$ & storage & network & laaS \\
\hline AWS & Second & First & First & First \\
\hline $\begin{array}{c}\text { Alibaba } \\
\text { Cloud }\end{array}$ & First & Second & Forth & Second \\
\hline Microsoft & Forth & Third & Third & Forth \\
\hline Google & Third & Forth & Second & Third \\
\hline
\end{tabular}

Next, Taobao and Alipay are the strongest advantages for Alibaba Cloud. Taobao and Alipay are projects of Alibaba. Now, Taobao is the largest e-commerce platform and Alipay is the largest mobile payment manufacturer in the world, every merchant who enters Taobao and Alipay is the beneficiary of Alibaba Cloud. Taobao and Alipay continuously accumulate data and ecommerce operation experience for Alibaba Cloud and providing data support and consumers for Alibaba Cloud, helping Alibaba expand its scale. Scale is the core of cloud computing, just like bank deposit, only the scale expands, the cost of cloud computing is controlled. That means Alibaba Cloud, Taobao and Alipay will enter a cycle of healthy growth.

Now, with the development of Internet technology and the continuous promotion of $5 \mathrm{~g}$ in China, the growth rate of the Chinese cloud market has obviously exceeded other regions. In the future, the growth of Alibaba Cloud is only a matter of time. 


\section{OVERSEAS E-COMMERCE}

In recent decades, e-commerce is developing rapidly under the support of internet information technology and online shopping have gained great popularity as a convenient means of commodity trading activities. This part will argue that Alibaba cannot be the number one in the global e-commerce industry and the best outcome for Alibaba is to share the market equally with leading competitors such as Amazon and eBay.

First of all, the total e-commerce market in North America ranks first in the world, followed by that in Europe. In the major developed countries such as the United States, Britain, Germany and France, the ecommerce market has formed a certain scale. The development of e-commerce has gone beyond the initial stage and high-speed development stage, so it is gradually slow. In this period, the competition of ecommerce enterprises is gradually fierce, and the platform situation is gradually taking shape. For North America, Amazon accounts for nearly half of the market share of our e-commerce. According to the estimation of eMarketer, a market research company, Amazon's share is close to $40 \%$ in 2020, which is the largest e-commerce platform in America that AliExpress is unable to match or surpass. Moreover, the US offline retail system is highly mature. There are not only Amazon and eBay, but also Wal Mart and best buy have their own online businesses and gain much customers attention. Although Alibaba has invested in many companies related to ecommerce business in the United States, and also tried different e-commerce models, such as social e-commerce, to attract local consumers, its strategy is experiencing setbacks. The most intuitive result is that Alibaba launched 11main in 2014, but one year later, it sold it at a low price. Therefore, the possibility of Alibaba's continued market share in the US is low. The situation in Europe is similar to that in the US, where there are mature retail channels. Amazon and eBay are the two most popular e-businesses in Britain, France and Germany. Also, compete with other local e-businesses, Alibaba's AliExpress occupy market share in Europe is difficult. Furthermore, in 2020, the global per capita e-commerce expenditure exceeds $\$ 2000$. In the global household ecommerce expenditure ranking, the top ten countries are Britain, the United States, South Korea, France, China, Australia, Canada, Japan, Israel and Germany. Among them, the highest per capita per year in Britain is \$4201, and the tenth in Germany is $\$ 1283$. Obviously, developed countries and China are the main consumers. Alibaba has performed well in Romania, Spain, Russia and other countries, but if it cannot occupy the major shares of Amazon and eBay in developed countries and only occupy emerging markets, it is obviously impossible for Alibaba to get obvious profit growth and greater revenue space.
Table 2. E-commerce market share in different regions

\begin{tabular}{|c|c|c|c|}
\hline Region & NO.1 & NO.2 & NO.3 \\
\hline Europe & Amazon & eBay & AliExpress \\
\hline $\begin{array}{c}\text { North } \\
\text { America }\end{array}$ & Amazon & eBay & Walmart \\
\hline $\begin{array}{c}\text { South } \\
\text { America }\end{array}$ & $\begin{array}{c}\text { Mercado } \\
\text { Libre }\end{array}$ & Americanas & $\begin{array}{c}\text { Amazon and } \\
\text { AliExpress }\end{array}$ \\
\hline $\begin{array}{c}\text { Middle } \\
\text { East }\end{array}$ & Trendyol & N11 & GittiGidiyor \\
\hline $\begin{array}{c}\text { South-East } \\
\text { Asia }\end{array}$ & Shoppe & Lazada & Tokopedia \\
\hline Australia & eBay & Amazon & Trade M \\
\hline Africa & Jumia & Souq & Konga \\
\hline China & Alibaba & JDcom & Buy Together \\
\hline
\end{tabular}

In the Middle East, Southeast Asia, Africa and South America, the consumption habits of residents have not yet been cultivated. Nowadays, the sales volume of ecommerce in the Middle East only accounts for about $2 \%$ of the total social retail sales. However nearly $50 \%$ of the population in the Middle East is under the age of 25 , which has an explosive growth of demand for high-tech and intelligent life, and there are a large number of rich people, whose per capita disposable income is very high in some major countries. EMarketer's data predicted that e-commerce in the Middle East will maintain an annual growth rate of about $20 \%$ in the next few years. For Alibaba, Amazon and other enterprises, there is still much space for development and market share to be occupied. According to the eMarketer, Amazon, eBay and AliExpress all are the top 3 in market share in Armenia, Kuwait, Bahrain, Qatar and other countries, but considering Alibaba's investment in Trendyol, which have over $80 \%$ of share, the largest e-commerce shareholder in the Middle East, it can be a big contributor to Alibaba's profit in the future. Then, from the perspective of geographical location, Southeast Asia is the main region for China to carry out trade cooperation with countries along the line and e-commerce activities conducting in the Southeast Asia market is high. In 2020, the Internet economy GMV of Southeast Asia close to 100 billion US dollars and in the last five years, the compound growth rate of Internet economy GMV of the major Southeast Asian countries, all exceeds $20 \%$. Shopee and Lazada are the top two e-commerce platforms in Southeast Asia. Considering that Alibaba is the main controlling party of Lazada, Alibaba has more advantages than major competitors such as Amazon and eBay. For Africa, the growth of e-commerce in Africa is fast, but at present, the market space of online shopping is not large, because the penetration rate of Africa's access to the network is low, and there are not enough 
facilities to meet the distribution and delivery conditions of online shopping. Although some e-commerce platforms such as Jumia have already occupied a certain market advantage, it is not difficult for Alibaba to enter the African market and take advantage of its capital to occupy first place in the market share. For the ecommerce market in South America, it has experienced many years of growth, local consumers have been through long-term market education, gradually develop online shopping habits. Nearly $60 \%$ of network coverage and 620 million people living in South America provide a huge consumer base for the development of ecommerce. The e-commerce market in South America has reached 20 billion US dollars, and the growth rate of the e-commerce market will be maintained for a long time. However, Mercado Libre, a South American ecommerce platform, occupying a major market share, with 160 million active users and more than 10 million sellers, dominates, while Alibaba and Amazon eBay do not open large markets in South America. If Alibaba does not seize the opportunity of rapid development, it may not have a place in South America.

In terms of domestic market share, according to Alibaba's results announcement, retail and wholesale revenue from China accounts for $71 \%$ of all group revenue, so the volume of domestic e-commerce business is much larger than that of foreign e-commerce business, which is also the main source of Alibaba's profits. However, the growth profit of Alibaba's e-commerce business in China is about 20\%, which slowed down. Although Alibaba, including taobao.com, tmall.com and judaosuan.com, still occupies a large market share, Alibaba is no longer the largest e-commerce platform for domestic users. Platforms such as Jingdong and Buy Together pose a great threat to Alibaba. Compared with tmall.com, Jingdong's logistics and self-operated credit have obvious advantages, while Buy Together has attracted a large number of emerging users in China's second and third-tier cities and rural areas using 10 billion subsidies. By the end of 2020, the number of active buyers of Buy Together will reach 788.4 million, while the number of active buyers of Alibaba will reach 779 million. At present, Alibaba's biggest dilemma in China is the network traffic dilemma. Tencent, another rival of Alibaba in China, owns chat and social platforms such as WeChat and QQ, which make Alibaba gradually lose its advantage in China's e-commerce industry through capital investment in jd.com and traffic support. Alibaba has not caught the opportunity of the development of the short video industry in recent years. The development of short video platforms such as Tiktok and Kwa Fu quickly robs the new traffic. Although Tiktok signed a framework agreement with Taobao, in recent bytes, it set up a business department of the firstclass business department. The short video platform traffic will not be supplied by Taobao alone. In short, the development of Alibaba's domestic e-commerce business is likely to meet the ceiling in the near future.

In conclusion, Alibaba's e-commerce business is mainly in China, and overseas e-commerce accounts for a relatively small proportion. Alibaba's domestic business growth slows down due to the fierce competition among domestic platforms in China. Although Alibaba develops rapidly in developing countries, its future high-profit business ceiling of ecommerce still depends on whether it can occupy more shares in major developed countries. Sharing the market equally with leading competitors such as Amazon and eBay in the world is the best forecast.

\section{CAINIAO NETWORK}

Cainiao Network Technology Co., Ltd. was jointly funded and established by Alibaba, SF Express and Santong Yida on May 28, 2013. Cainiao Network's revenue in the fourth quarter of 2019 was 7.518 billion, a $67 \%$ increase compared with the same period last year. The same year November, Alibaba made a follow-up investment in Cainiao and its shareholding rose from $51 \%$ to $63 \%$. Then Cainiao Network's market value made to 190 billion in August 2020. According to the annual report, the income that Cainiao brings to Ali is increasing every year, and the Cainiao Network's proportion of the total income of Alibaba is also increasing year by year. According to the current trend, the revenue brought by Cainiao Network is increasing year by year, so according to the trend in recent years, Cainiao Network still has the space for growth.

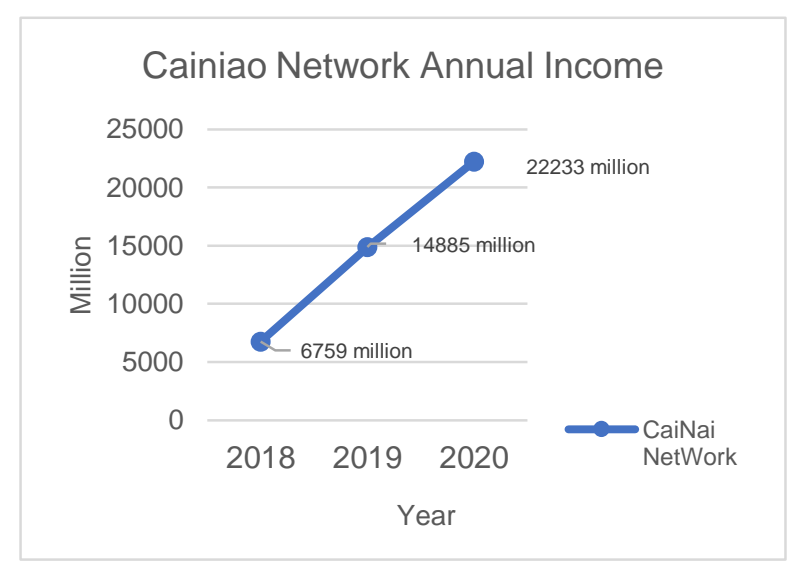

Figure 4 Cainiao's revenue as a percentage of Alibaba's total revenue

However, the future growth of Cainiao Network depends on two issues. The first part are that YTO, STO, ZTO and YUNDA as third-party partners, will they continue to cooperate with Cainiao? Then the second is that the impact of SF Express JD and J\&T as external competitors on CaiNao in the domestic market.

The first issue. After cooperating with CaiNao NetWork, there would always be some problems with the 
net income of third-party partners. There would show a graph.

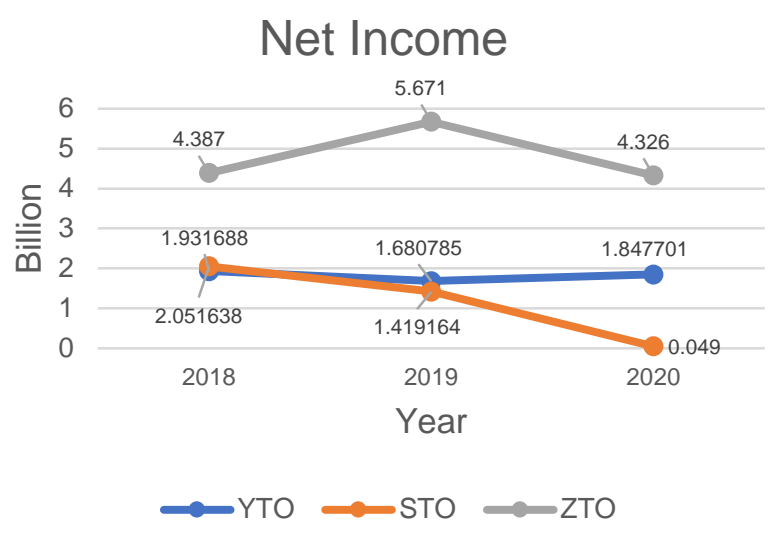

Figure 5 Net income of third-party companies

These data show that third-party partners working with Cainiao had experienced negative growth rates of net income in the period from 2018 to 2020. Except for ZTO, the net profit of other Third-party partners in 2020 has dropped a lot compared to 2018. From the end of 2019 to the beginning of 2021, only SF Express and ZTO in the top five express delivery companies in China achieved positive growth in market value. Then all of STO, YTO, and YUNDA achieved negative growth in market value. And four of the five express companies are third-party cooperative companies of Cainiao, only ZTO in those four companies got 66.3 percentage of the growth rate in market value. The reason why ZTO have a positive growth rate is that ZTO is one of the leading domestic delivery company, and it completed approximately 17 billion transactions in 2020, accounting for $20.4 \%$ of the market. As the third-party partners with CaiNao NetWork, they are bundled with Ali's Taobao and Tmall. As a partner of Ali's Cainiao, they must priority ensuring the normal operation of Taobao and Tmall and the rights of consumers. Therefore, Taobao and Tmall will adjust the cost of express delivery every year. From 2013 to 2019, the average price of national express delivery dropped from 15.7 to 11.8 , a large part of the reason is the bundling of third parties with CaiNao NetWork.

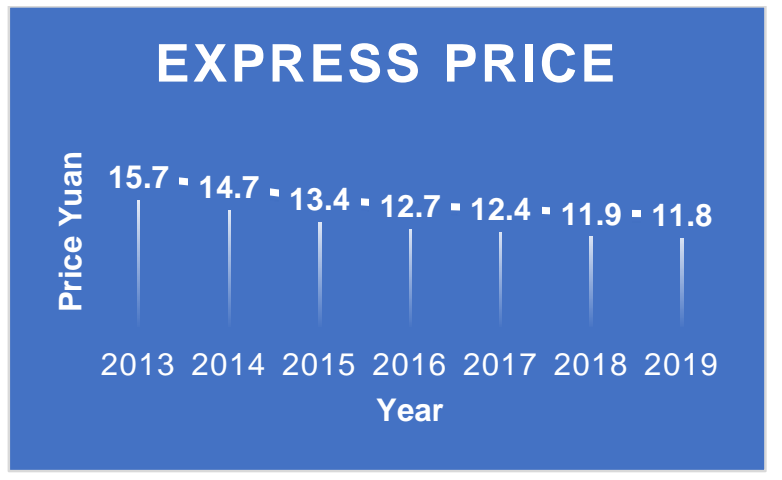

Figure 6 Express average price
This also brought economies of scale. On the Double Eleven Day of 2019, Cainiao's network logistics orders reached 1.294 billion, a year-on-year increase of $24 \%$. However, the reduction in prices still caused losses for third-party partners. The bundling with Cainiao makes their net profit growth rate negative at some point. According to the graph "Net Income" and "CaiNao Network Annual Income", In the period from 2017 to 2020, the third-party partners would have some situations of net profit decreasing compared with the previous year in some points. But, Cainiao NetWork's Annual Income almost straight up from 2018 to2020. This shows that Cainiao's price restrictions on partners had brought huge profits to Cainiao itself and squeezed the partners at the same time, but third-party partners will not give up their cooperation with Cainiao. Although the cooperation with Cainiao has brought them a price loss, their bundling with Cainiao has brought them huge customer traffic. So even if their net profit growth rate is negative, their net profit will not be negative. According to the current trend, the price of express will keep decreasing in next fewer years. Therefore if the third-party panters leave the building with Cainiao, they will lose consumer traffic at the same time as the price is lost. This also shows that leaving the cooperation with Cainiao will bring huge losses for them, and according to the trend in recent years, it is difficult for them to recover their previous revenue. So third-party partners will eventually continue to cooperate with Cainiao.

The second issues. SF, JD, J\&T are the main opponents of the Cainiao alliance. They bring some shocks to the Cainiao alliance in the current express market.

The first one, SF. As one of the leaders in the domestic express delivery market, SF Express occupies the top position in the revenue of domestic express companies. In 2020, SF got 153.98 billion revenue, and YTP STO and ZTO as the third party cooperating with Cainiao, their revenue in 2020 are 34.907 billion 21.566 billion and 25.214 billion. According to the revenue data, the total revenue of the third-party companies cooperating with Cainiao is less than that of SF Express, and SF also got a net income of 6.93 billion in 2020 . According to these data, SF is a huge opponent for the CaiNao alliance. However, in terms of market share, SF Express is less than the third-party cooperative company of Cainiao. In 2020, SF only complete 8.14 billion transactions, but ZTO YUNDA YTO, and STO complete 17 billion 14.18 billion 12.65 billion, and 8.82 billion. 


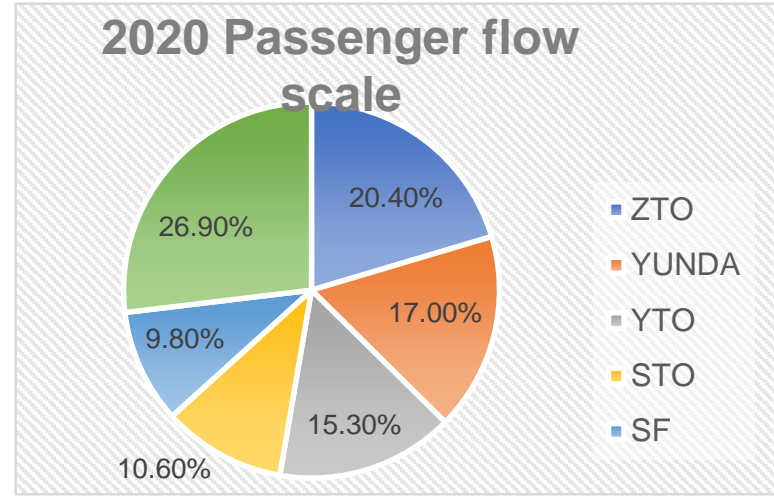

Figure 7 Market Share

Therefore, the Cainiao alliance completely surpassed SF Express in terms of market share, and offset the revenue gap. SF Express's threat to Cainiao is not great. The second, JD. As Cainiao's second competitor, JD also poses a certain threat to Cainiao Alliance. JD's model is not like Cainiao with a third party, JD is through the establishment of warehouses in the whole country. Then they can implement the 24-hour receive delivery model, on the contrary, Cainiao is 72 hours. Cainiao's delivery time is a little worse than JD, but JD's logistics is aimed at customers on its own e-commerce platform, and will not extend to the passenger flow of other platforms. For example, Taobao and Tmall. Therefore, both JD Logistics and Cainiao Network are targeting the passenger flow of their e-commerce platforms to complete the delivery. So in terms of market competition, JD is not a big threat to Cainiao. Even if the logistics service and speed of Cainiao Alliance are not as good as JD, but Ali's e-commerce platform has a stable passenger flow, so JD's threat is not very big. The third is J\&T. In March 2020, J\&T entered the Chinese market. J\&T's entry directly adopted the method of the price war and cooperate with Pinduoduo. J\&T reduce the average price of express delivery by $11 \%$ in 2020 , and it makes the third-party monopoly price of Cainiao collapsed. Relying on the price advantage, J\&T has achieved $100 \%$ coverage of the transportation station center nationwide within ten months and reached an astonishing 6 million orders a day. After a year, it reached 20 million daily orders. The entry of J\&T has brought unprecedented pressure to Cainiao Network. This forces Cainiao to make lost customers back through changing the delivery model, and the effect is obvious. On May 13th, Ali released the financial report for the fourth quarter of 2021 and the full-year financial report. In the report, the external revenue of Cainiao Network in the fourth quarter increased by $11 \%$ year-onyear and reached 9.9 billion, and annual external income was 37.2 billion yuan, a year-on-year increase of $68 \%$. Although J\&T has a great impact on Cainiao's market through price wars, according to the financial report data, Cainiao's changes have enabled them to recover most of the market. According to the current trend, It may continue to grow in the future. Although J\&T currently poses a great threat to Cainiao. However, the price war method will not keep forever. If the price keeps dropping, it will only lead to the collapse of the market. This is a bad way of market competition. In the long run, the price should rise to the level before the price war. Therefore, even though J\&T poses a great threat to CaiNai at present, this kind of threat should gradually shrink in the future.

Therefore, based on the above data and analyses, Cainiao has a lot of space for growth in the next few years, and it should bring greater benefits to Alibaba.

\section{FINTECH}

The first question that needs to be asked is that how Fintech works in China. Nowadays, Most Fintech innovation in China is nothing but internet Finance. With the progression and improvement of information technology in China, internet companies are attempting countless ways to earn money by new tools of the information era. Actually, the same progression like MIS systems used in China's central government-owned enterprise and cloud computing platform based on new 5G technology have not gained so much dispute as internet Finance in China. With China's government making more and more opening and reforming policies to support the using of financial tools which used by capitalist countries several decades and the building of innovating companies. The internet companies started their own financial services. These internet company occupied the financial market which traditional banks hardly reach by building their special and high-efficiency credit system and guiding their user from their basic internet platform. For instance, Ant Financial built with the help of Alibaba, Wechat financial based on the Tencent social network system. What is more, these internet companies are also skilled in absorbing idle capital from their users. For example, Numbers of internet company started their financial service by OPM. Supported by the analysis above, the key point of the success of internet companies is the data collected from their users. If China's government stop supervising, Everybody can start their Fintech career by buying software to lend money to people, lending some money from others, and getting information of their target customers by the data bought in some special ways - One precise information of a simple person is sold only 0.1 CNY in the black market. So, why these data can be bought? An important reason is that numbers of hackers are attacking internet companies' database. For instance, Ac Fun, a famous Chinese video website, attacked by hackers in 2018, and thus leaked nearly ten millions data of users.

But, the most important question is not why the data are leaked and can be bought. The question we have to ask is why the data, the products made by the social connecting between the people, are becoming the intangible assets of the internet companies which are 
providing the social contracting services. These data should be the assets of users of internet financial companies but not assets of the companies. Surely, this paradox is the mean caution of the disruption and chaos made by the fintech company of China.

In conclusion:

Data collected+Credit and customer system+OPM and money absorbed from different place $=>$ Big internet companies' internet financial service.

Data bought+Money+IT service bought from others $=>$ briefcase companies' financial service.

What is more, it is important to explain the property of China's internet finance. China government's view of new technology and financial tools is actually opening. For example, bitcoins, a type of decentralize fintech product, can be discussed and invested easily in China before it produced several extremely destructive waves of bubbles and chaos in China's Cryptocurrency market and computer hardware market. Compared with Cryptocurrency, the innovations of internet finance have developed the living quality of the whole society of China and other countries. Products like Wechat Pay, Alipay changed people's life ever since. Therefore, China's government may prefer to give some guidance to the field of internet finance, but not to stop and destroy it. Besides, the needing for money from the whole China society is inevitable. As the progressing of China's economy, the needing for financing and investing is getting much bigger than before. Meanwhile, restricted by national and international policies and regulations as "The Basel Accords" series, it is hard for banks to lend money to small and medium-sized customers, who are low credit in common. On contrary, IT corporations are willing to lend money to them. The existence of supply and demand boosts the business of internet finance in China. Meanwhile, Compared with the numbers of permission need to set up a traditional financial corporation, there is much less work need to make for building a technology company. Meanwhile, it is hard for nowaday laws to separate the technology company which provide the financial service and the financial company which provide the financial service. What is more, identified as a technology company which has a much more $\mathrm{P} / \mathrm{E}$ ratio in the market, the internet financial companies priced much higher than a traditional financial company. Besides, lots of internet financial company lend money at even a $20 \%$ interest rate per year, which brings high profits to these firms.

From the discussion above, it is wise for us to understand the excessive prosperity of internet finance will finally be limited in some way by China's government: it may enter the internet financial market someday after the whole market matured. In the proposal, a central data bank controlled by China's government will be made to deal with and restore all of the data made by IT companies in the information age. Because The big data made in the information is thought to be priceless. The government have to make sure and supervise that these pieces of information are safe and used in rational ways. Besides, these data can help the government to build up their information systems better. Also, the people whose data was collected can have a better chance to reach their own data than before with the help of the data department. The department, which may be called the central data bank, can control countless servers which can be used to save and process the data directly or indirectly, which may set up by the central government, or the local government of China. But no matter how all of the IT company have to save and use their collected data in the servers controlled by the department. Besides, To enhance international competitiveness, the data department may start its work by building several monopoly data corporations. This centralized data department, the central data bank, and their subordinate data companies may locate in southwest China in the future if the relative department is approved. Because that area can provide the cheapest electricity, and many people in west China can find their job in this plan. What is more, to keep internet financial stable and matured internet company away from monopoly. Law to stop other companies to reach this market and to make the market works like the markets of electricity, water purifying, traditional security, traditional banking will be made in the future. Furthermore, the laws which prevent matured huge financial company to monopoly the fintech fields by their basic internet and technology business, their internet business and their financial business will be made one day. Finally, it is sure that fintech is not internet finance. So, even fintech is thought to be internet financial in China, actually, we can not foresee the future's financial innovation. Just like the options, swaps, futures are also the "fintech" in the 19th century, internet finance will finally become a simple financial tool for investors and managers to use.

\section{CONCLUSION}

This research was conducted to evaluate Alibaba's future growth in the aspects of Alibaba Cloud, Cainiao Network, global e-commerce and Fintech. Despite the fierce competition in the cloud service industry, Alibaba cloud can occupy the leading position in the cloud computing industry in China and compete with international cloud service providers for future leadership. Moreover, in the next few years, the growth of the Cainiao Network business will help Alibaba stabilize its domestic market share and earn more profits. From the perspective of future potential, Alibaba's e-commerce business is still one of the main revenue sources of Alibaba group, but it is still difficult for Alibaba ecommerce to become the first e-commerce in the world. Finally, although It is difficult to meet financial 
innovation in the future, the development of financial technology in China will be steady, rapid and healthy.

\section{REFERENCES}

[1] Yu X, Zhao Y, Yang W. The innovation of ecommerce financial service product based on cloud computing-taking Alibaba Finance as an example[C]// Service Systems and Service Management (ICSSSM), 2013 10th International Conference on. 2013.

[2] Shi Yuxi, Hu Yihan, he Yusheng, Li Weixuan. On the development of cloud service companies in the era of digital economy -- Taking Alibaba cloud as an example [J]. Contemporary accounting, 2020 (03): $3-5$

[3] Mei Yaxin. Cloud computing 2020, the Matthew effect is intensifies, and the industry is blooming [J]. Communication World, 2020(34): 28-29.

[4] Han, Y, Gan, J. Application and Influence of Big Data in the Logistics Industry-Take Cainiao Network as an Example. International Conference on Transportation Engineering (pp.2141-2144).

[5] Ye, B, Jia, Z, Xin, Z, Lin, L. (2016). Research on the Express Delivery Delay Prediction Based on Neural Network in the Background of Big Data. International Conference on Electronic.

[6] Tan, X, Shu, Y, Lu, X. Cheng, P. , \& J Chen. (2014). [ieee 2014 ieee international congress on big data (bigdata congress) - anchorage, ak, usa (2014.6.272014.7.2)] 2014 ieee international congress on big data - characterizing and modeling package dynamics in express shipping service network. 144151 .

[7] Lu, L. (2018). Decoding Alipay: Mobile Payments, a Cashless Society and Regulatory Challenges. Social Science Electronic Publishing.

[8] Zhao, Y. (2017). Research on the consumer finance system of ant financial service group. American Journal of Industrial \& Business Management, 7(5), 559-565.

[9]Qiu, Peipei, S.M. Sloan School of Management. (2018). Build Alipay ecosystem in Brazil.

[10] Jing Z, Shan W, Huang W V. A study of B2B emarket in China: E-commerce process perspective[J]. Information \& Management, 2008, 45(4):242-248.

[11] Hussain A, Mkpojiogu E, Almazini H, et al. AIP Conference Proceedings [Author(s) THE 2ND INTERNATIONAL CONFERENCE ON APPLIED SCIENCE AND TECHNOLOGY 2017
(ICAST'17) - Kedah, Malaysia (3-5 April 2017)] Assessing the usability of Shazam mobile app[C]// American Institute of Physics Conference Series. American Institute of Physics Conference Series, 2017:020057.

[12] Laruccia M M. Social Networks and Post-Purchase Behavior: Analysis of the Content of the Mentions on AliExpress[J]. SSRN Electronic Journal, 2018. 